JIKAP PGSD: Jurnal Ilmiah Ilmu Kependidikan

Vol, 4. No,1. Tahun 2020

e-ISSN: 2597-4440 dan p-ISSN: 2597-4424

This work is licensed under a Creative Commons Attribution

4.0 International License

\title{
Penanaman Sikap Sosial Pada Pembelajaran Pkn Di Sekolah Dasar Negeri KIP Maccini Makassar
}

\author{
Andi Naila Milawati ${ }^{1}$, Nursalam ${ }^{2}$, Roesleny ${ }^{3}$ \\ ${ }^{1,2,3}$ Pendidikan Dasar Program Pascasarjana, Universitas Muhammadiyah Makassar \\ E-mail: ${ }^{1}$ amilawati414@yahoo.com \\ 2nursalam@gmail.com \\ roesleny@gmail.com
}

\begin{abstract}
Abstrak. Penelitian ini bertujuan untuk mendeskripsikan mengenai rancangan penanaman sikap sosial dan teknik penilaian sikap sosial siswa di kelas IV SDN KIP Maccini Makassar pada mata pelajaran PKn. Teknik pengumpulan data menggunakan observasi, wawancara, dan dokumentasi Teknik analisis data dalam penelitian ini, menggunakan analisis deskriptif kualitatif dengan proses analisis data menggunakan model interaktif. Berdasarkan hasil penelitian dapat diketahui bahwa (1) cara guru menanamkan sikap sosial melalui pembelajaran PKn kelas IV di SDN KIP Maccini Kota Makassar (a) Guru senantiasa mengajarkan solidaritas, tenggang rasa, dan kerjasama kepada siswa pasa saat pembelajaran berlangsung. (b) Guru menerapkan tata tertib baik didalam kelas maupun diluar kelas dan pengamalan nilai-nilai pancasila dengan kehidupan sehari-hari. (c) Pemasangan slogan atau poster yang berkaitan dengan sikap sosial didalam kelas yang bertujuan untuk selalu mengingatkan siswa agar tetap bersikap baik. (d) Keteladanan ditunjukkan oleh guru dengan berangkat lebih awal dari siswa dan ikut menjenguk jika terdapat guru atau siswa yang sakit. (e) Kegiatan rutin seperti membiasakan siswa untuk bersalaman, berdoa, piket, dan menerapkan 5S (senyum, salam, sapa, sopan, dan santun). (2) Serta cara penilaian yang dilakukan guru dengan menggunakan lembar penilaian sikap sosial yang meliputi interpersonal yaitu diri sendiri dan antarpersonal yaitu antar teman.
\end{abstract}

Kata kunci: Penanaman Sikap Sosial, Pembelajaran Pkn

Abstract. This research aims to describe the design of social attitudes and assessment techniques for students ' social attitudes in class IV of SDN KIP Maccini Makassar on the subject of PKn. Data collection techniques using observation, interviews, and The data Analysis techniques documentation in this study, uses qualitative descriptive analysis with the process of analyzing the data using interactive models. Based on the results of the study can be known that (1) the way teachers instill social attitudes through the study of PKn class IV at SDN KIP Maccini Makassar (a) teachers always teach solidarity, tolerance, and cooperation to students when The learning process. (b) The teacher implements the code of conduct both in class and outside class and the practice of the values of Pancasila with daily life. (c) The installation of a slogan or poster related to a social attitude in a class that aims to always remind students to remain good. (d) The accuracy is shown by the teacher by departing earlier than the student and participating in if there is a sick teacher or student. (e) Routine activities such as familiarizing the students to pray, praying, picket, and applying $5 \mathrm{~S}$ (smile, Greetings, Sapa, polite, and polite). (2) as well as the way of judgment by the teacher 
by using a social attitude assessment that includes interpersonal self, which is among other people.

\section{Keywords: Planting Social Attitudes, Pkn Learning}

\section{PENDAHULUAN}

Pendidikan memiliki peranan penting untuk masa depan suatu bangsa dan negara, karena pendidikan merupakan upaya untuk membebaskan masyarakat dari kebodohan, kemiskinan, dan penderitaan. Indonesia sebagai negara berkembang yang membutuhkan Sumber Daya Manusia (SDM) berkualitas sangat memperhatikan pendidikan. Undang-undang No.20 Tahun 2003 tentang Sistem Pendidikan Nasional menyatakan bahwa pendidikan nasional berfungsi mengembangkan kemampuan dan membentuk watak serta peradaban bangsa yang bermartabat dalam rangka mencerdaskan kehidupan bangsa.

Pengimpelementasian kurikulum 2013, maka bangsa Indonesia ke depan akan menjadi bangsa dan negara yang bermartabat, yang dapat mensejajarkan diri dengan bangsa-bangsa lain dalam tatanan global. Pemerintah telah melakukan berbagai standarisasi dan profesionalisasi pendidikan, seperti yang dituangkan dalam Peraturan Pemerintah No 19 tahun 2005 tentang Standar Nasional Pendidikan (SNP), yang telah disempurnakan dalam peraturan pemerintah N0 32 Tahun 2013.

Kurikulum 2013 dikembangkan berdasarkan persoalan yang sangat penting, karena kurikulum harus senantiasa disesuaikan dengan tuntutan zaman dan harus menghadapi berbagai masalah serta tantangan masa depan yang semakin lama semakin rumit dan kompleks.

Persoalan sikap sosial menjadi bahan pemikiran sekaligus keprihatinan bersama karena negara ini dikatakan sedang menderita krisis sikap sosial. Krisis ini ditandai dengan maraknya tindakan kriminal, seperti tawuran antar pelajar, meningkatnya pergaulan bebas, maraknya angka kekerasan anak-anak dan remaja, yang seringkali menjurus pada tindak kekerasan yang meresahkan masyarakat, korupsi yang mewabah dan merambah pada semua sektor kehidupan masyarakat, bahkan pembunuhan.

Fenomena tersebut jelas telah mencoreng citra pelajar dan lembaga pendidikan, karena banyak orang berpandangan bahwa kondisi demikian berawal dari apa yang dihasilkan oleh dunia pendidikan.

Sapa'at (2014) menyatakan sikap sosial terlanjur disepelekan padahal kompetensi tanpa sikap sosial, kerusakan hasilnya. Jika mencontek, menghina teman, tidak disiplin, baku hantam antar siswa di kelas atau terkesan dibiarkan dan tidak pernah tuntas diselesaikan. Sekolah bukan satu-satunya pihak paling bertanggung jawab, tetapi komitmen, konsistensi, dan kreativitas sekolah dalam merancang sistem pendidikan yang bisa mengatasi perilaku buruk siswa, itulah karya sekolah sesungguhnya

Atas kondisi demikian, semua pihak sepakat mengatasi persoalan kemerosotan dalam dimensi sikap sosial ini. Sebenarnya, persoalan sikap sosial atau moral tidak sepenuhnya terabaikan oleh lembaga pendidikan. Akan tetapi, fenomena-fenomena yang terjadi menunjukkan bahwa ada kegagalan pada institusi pendidikan dalam menumbuhkan manusia Indonesia yang bersikap sosial dan berakhlak mulia.

Sementara itu, mata pelajaran pendidikan agama dan pendidikan PKn yang diharapkan berkontribusi dalam hal pembentukan sikap sosial, tampaknya lebih mengajarkan pada dasar-dasar agama, serta hak dan kewajiban warga negara sementara akhlak atau kandungan nilai-nilai kebaikan belum sepenuhnya disampaikan, akibatnya murid hanya tahu agama dan tahu aturan tapi tidak diinternalisasi. Karena itu tidaklah mengherankan jika dijumpai inkonsistensi antara apa yang diajarkan di sekolah dan apa yang diterapkan anak di luar sekolah (Megawangi, 2004:80).

Salah satu upaya yang dapat dilakukan ialah dengan mengembangkan kurikulum. Terkait dengan diberlakukannya Kurikulum 2013 ada beberapa faktor yang menjadi alasan dalam mengembangkan kurikulum, seperti tantangan masa depan dan berbagai fenomena negatif yang terjadi di masyarakat. Tantangan masa depan dimaksudkan bahwa peserta didik harus dipersiapkan dengan ilmu pengetahuan dan teknologi, serta keterampilan yang sebagai bekal menggapai kesuksesan di masa depan.

Hasil survei awal yang dilakukan peneliti kondisi faktual di lapangan SDN KIP Maccini Makassar masih terlihat 
kecenderungan sebagian besar orang tua menyerahkan sepenuhnya pendidikan sikap sosial pada sekolah sehingga tujuan yang akan dicapai belum seperti yang diharapkan. Dan melihat fenomena yang terjadi di lingkungan sekolah SDN KIP Maccini masih terlihat peserta didik tidak bisa menjawab pertanyaan yang diajukan oleh teman atau guru, kurang aktif terlibat dalam kegiatan kelompok, masih ada peserta didik yang terlambat hadir disekolah, kurangnya kesadaran peserta didik untuk mengerjakan tugas yang diberikan oleh guru, peserta didik tidak mandiri, dan masih terdapat siswa yang kurang menjaga lingkungan belajaranya. Berdasarkan uraian tersebut, maka dibutuhkan pengetahuan bagaimana menggabungkan antara sikap sosial dalam pembelajaran PKn secara efektif agar mudah diterapkan dan dipahami peserta didik.

Berdasarkan observasi yang dilakukan, Sekolah Dasar KIP Maccini Makassar adalah salah satu sekolah sasaran untuk dijadikan percontohan kurikulum 2013 di Kota Makassar. Guru-guru SD KIP Maccini Makassar telah mengikuti pelatihan dan pendampingan kurikulum 2013. Hal ini menjadi landasan peneliti memilih SDN KIP Maccini Makassar untuk melakukan Penanaman Sikap Sosial dalam Pembelajaran PKn yang sesuai dengan kurikulum 2013.

\section{METODE PENELITIAN}

Pendekatan penelitian ini adalah kualitatif bertujuan untuk mendeksripsikan mengenai rancangan penanaman sikap dan teknik penilaian sikap sosial siswa di kelas IV SD Negeri KIP Maccini Makassar pada mata pelajaran pendidikan kewarganegaraan ( $\mathrm{PKn})$.

Lokasi penelitian ini dilakukan di SD Negeri KIP Maccini Makassar, terletak di Kerung-Kerung Nomor 69A Kelurahan Maccini Gusung Kecamatan Makassar Provinsi Sulawesi selatan. Adapun pemilihan lokasi penelitian dilandasi bahwa SD Negeri KIP Maccini Makassar telah mengimplementasikan kurikulum 2013 sejak diberlakukan oleh pemerintah dan guru-guru di sekolah tersebut telah mengikuti pelatihan kurikulum 2013.

Jenis data dalam penelitian ini adalah data primer yang diperoleh langsung dari informan dan data sekunder berupa dokumen-dokumen yang berhubungan dengan permasalahan dan laporan-laporan penelitian. Instrumen dalam penelitian ini adalah peneliti sendiri dan alat pengumpulan data penunjang berupa pedoman wawancara. Teknik analisis data dalam penelitian ini, menggunakan analisis deskriptif kualitatif dengan proses analisis data menggunakan model interaktif.

Informan dalam penelitian ini adalah kepala sekolah, guru PKn kelas IV yang terdiri dari 2 orang yaitu, guru kelas IV A 1 orang dan guru kelas IV B 1 orang serta 6 orang siswa kelas IV, yang penentuan informannya dilakukan dengan teknik purposive sampling, di mana pemilihan dilakukan secara sengaja berdasarkan kriteria yang telah di tentukan dan ditetapkan berdasarkan tujuan penelitian.

Teknik pengumpulan data dalam pengamatan ini menggunakan metode observasi langsung, peneliti melakukan pengamatan secara langsung dalam situasi yang sebenarnya.

1. Metode observasi, yang digunakan adalah observasi nonpartisispan.karena peneliti bukan bagian dari subjek yang diteliti, tetapi peneliti hanya sebagai pengamat yang tidak mengambil bagian dalam aktivitas subjek yang diteliti, agar penelitian ini tidak menjadi bias terhadap data yang dikumpulkan, pengamatan yang dilakukan dengan jalan mengamati cara guru menanamkan sikap sosial pada siswa dalam proses pembelajaran dengan melihat tiga aspek sosial siwa yaitu, disiplin, tanggung jawab dan percaya diri, pencatatan secara sistematik terhadap gejala-gejala yang tampak. Pada objek penelitian sehingga data yang diperoleh dapat dipertanggung jawabkan.

2. Wawancara, digunakan untuk mengumpulkan data tentang cara penanaman sikap sosial pada pembelajaran PKn dikelas IV SD Negeri KIP Maccini Makassar yang bersumber dari kepala sekolah, guru kelas IV A dan IV B serta 2 orang siswa kelas IV A dan 2 orang siswa kelas IV B. data yang diperoleh dari metode wawancara digunakan untuk melengkapi data yang diperoleh dari metode Observasi), sehingga data yang diperoleh lebih lengkap dan mendalam. Metode wawancara yang digunakan adalah wawancara terstruktur. Wawancara terstruktur dilakukan dengan cara mengajukan pertanyaan sesuai pedoman wawancara tentang penanaman sikap sosial siswa. Sedangkan wawancara tidak terstruktur dilakukan dengan menanyakan langsung dan spontan tanpa ada pedoman wawancara.

3. Dokumen, digunakan untuk mengumpulkan data tengtang rancangan penanaman sikap 
sosial dalam pelajaran PKn yang dibuat oleh guru kelas IV SD Negeri KIP Maccini Makassar. Pengumpulan data dengan metode dokumentasi dilakukan untuk mengumpulkan rancangan penanaman sikap sosial dalam bentuk rencana pelaksanaan pembelajaran (RPP) pada semester genap dan tahun ajaran 2018/2019 yang telah dibuat guru. Fokus penelitian adalah pembudayaan sikap sosial dari kompetensi inti-2 yang terintegrasi dalam pengajaran kompetensi inti-3 dan kompetensi inti-4 pada pembelajaran pendidikan kewarganegaraan (PKn).

Keabsahan data diterapkan dalam rangka membuktikan kebenaran temuan. Hasil penelitian dengan menggunkan teknik triangulasi. Menurut Moleong (2014: 330) triangulasi adalah teknik pemeriksaan keabsahan data yang memanfaatkan sesuatu yang lain diluar data itu untuk keperluan pengecekan atau sebagai pembanding terhadap data itu. Ada empat macam triangulasi sebagai teknik pemeriksaan yaitu memanfaatkan penggunaan sumber, metode, penyidik dan teori.

Pertama triangulasi dengan sumber. Membandingkan dengan mengecek balik drajat kepercayaan suatu informasi yang diperoleh melalaui sumber-sumber lainnya. Misalnya untuk data tentang penanaman sikap sosial pada pembelajaran PKn yang diperoleh dari siswa, peneliti dapat membandingkan dengan sumber-sumber lainnya, seperti guru dan kepala sekolah.

Kedua, triangulasi dengan metode mengecek derajat kepercyaan penemuan hasil penelitian dengan beberapa metode pengumpulan data. Misalnya data mengenai penanaman sikap sosial siswa pad apembelajaran PKn diperoleh melalaui metode observasi dan wawancara, sehingga kebenaran dan keabsahan data dapat dipertangung jawabkan.

Ketiga, triangulasi dengan penyidik, membandingkan hasil seorang analis dengan analis yang lainnya, untuk mengecek kembali keterpercayaan data.

Keempat, triangulasi dengan teori ini sebagai penjelasan pembanding artinya apabila peneliti telah menguraikan pola, hubungan dan memberikan penjelasan yang muncul daria analisis tersebut peneliti harus mencari penjelasan pembanding, baik secara induktif maupun logika.

\section{HASIL DAN PEMBAHASAN}

Berdasarkan hasil penelitian dapat diketahui bahwa (1) cara guru menanamkan sikap sosial melalui pembelajaran PKn kelas IV di SDN KIP Maccini Kota Makassar (a) Guru senantiasa mengajarkan solidaritas, tenggang rasa, dan kerjasama kepada siswa pasa saat pembelajaran berlangsung. (b) Guru menerapkan tata tertib baik didalam kelas maupun diluar kelas dan pengamalan nilai-nilai pancasila dengan kehidupan sehari-hari. (c) Pemasangan slogan atau poster yang berkaitan dengan sikap sosial didalam kelas yang bertujuan untuk selalu mengingatkan siswa agar tetap bersikap baik. (d) Keteladanan ditunjukkan oleh guru dengan berangkat lebih awal dari siswa dan ikut menjenguk jika terdapat guru atau siswa yang sakit. (e) Kegiatan rutin seperti membiasakan siswa untuk bersalaman, berdoa, piket, dan menerapkan 5S (senyum, salam, sapa, sopan, dan santun). (2) Serta cara penilaian yang dilakukan guru dengan menggunakan lembar penilaian sikap sosial yang meliputi interpersonal yaitu diri sendiri dan antarpersonal yaitu antar teman.

Berdasarkan hasil observasi, wawancara dan dokumentasi dengan kepala sekolah, guru kelas dan siswa di peroleh data sebagai berikut:

1. Cara guru menanamakan sikap sosial melalui pembelajaran PKn kelas IV di SDN KIP Maccini Makassar

a. Guru senantiasa mengajarkan tentang solidaritas dengan memberikan contoh langsung, misalnya pada saat piket didalam kelas siswa dengan sengaja diberikan arahan untuk saling tolong menolong membantu teman yang sedang bertugas piket, serta membentuk kelompok dengan cara yang menyenangkan dan memasukkan nilai solidaritas dengan mengajarkan siswa cara berbagi permainan maupun makanan.

b. Guru menerapkan tata tertib baik didalam kelas maupun diluar kelas. Guru harus memberikan contoh yang baik kepada murid, agar murid juga dapat mengikuti yang dilakukan oleh gurunya. Misalnya guru melarang siswa makan dan minum didalam kelas, guru juga harus melakukan hal yang sama. Guru dan siswa mempunyai tanggung jawab yang sama dalam hal kebersihan lingkungan sekolah, bukan hanya siswa yang bertugas membersihkan lingkungan sekolah tapi guru juga harus turut memberikan contoh 
dengan cara bersama-sama siswa melakukan gotong royong.

c. Guru melakukan pemasangan slogan atau poster yang berkaitan dengan sikap sosial didalam kelas yang bertujuan untuk selalu mengingatkan siswa agar tetap bersikap baik, dan mematuhi setiap tata tertib sekolah.

d. Guru menunjukkan keteladan dengan datang lebih awal dan menyapa siswa sebelum masuk didalam kelas. Dengan cara seperti ini siswa juga diyakini akan lebih bersemangat untuk belajar, siswa merasa mendapatkan perhatikan yang sama dengan dilingkungan rumahnya.

e. Mengajarkan kepada siswa untuk memiliki rasa peduli saat ada teman mereka yang lagi sakit, dengan cara ikut serta menjeguk siswa yang lagi sakit.

f. Siswa selalu ditanamkan denga nilai-nilai pengamalan pancasila dengan kehidupan sehari-hari.

2. Penilaian sikap sosial melalui pembelajaran PKn kelas IV di SDN KIP Maccini Makassar

Cara penilaian yang dilakukan guru dengan menggunakan lembar penilaian sikap sosial yang meliputi interpersonal yaitu diri sendiri dan antarpersonal yaitu antar teman. Guru menilai setiap sikap siswa baik pada saat pembelajaran maupun pada saat interaksi dengan antarteman.

\section{SIMPULAN DAN SARAN}

Keteladanan yang guru tunjukkan adalah berangkat lebih awal dari siswa dan ikut menjenguk jika terdapat guru atau siswa yang sakit. Kegiatan spontan dengan cara menegur dan menasehati jika ada siswa yang kurang sopan atau melakukan perbuatan yang kurang baik.

Pengkondisikan siswa dengan cara memasang poster atau slogan yang berkaitan dengan sikap sosial untuk memotivasi siswa agar bersikap yang baik. Guru juga mengajarkan solidaritas, tenggang rasa, dan kerjasama kepada siswa pada saat pembelajaran berlangsung. Penanamkan sikap sosial melalui pengintegrasian dalam mata pelajaran dengan cara menghubungkan dan mengembangkan materi yang sedang dipelajari dengan nilai-nilai sosial

Bagi Guru sebaiknya tetap mempertahankan dan meningkatkan keteladanan sikap sosial kepada siswa-siswanya, memberikan nilai-nilai sosial dan membudayakan siswa untuk bersikap sosial dalam kehidupan sehari-hari di sekolah dan senantiasa memberikan motivasi kepada siswa - siswanya agar selalu memiliki sikap sosial yang baik. Bagi Kepala Sekolah sebaiknya meningkatkan pembinaan terhadap guru-guru yang ada di SDN KIP Maccini Makassar agar dapat mempertahankan dan meningkatkan keteladanan sikap sosial kepada siswa-siswanya. Bagi Siswa sebaiknya senantiasa meningkatkan dan membudayakan sikap sosial dalam kehidupan sehari-hari baik di sekolah maupun di rumah.

\section{DAFTAR RUJUKAN}

Ayu, Ida 2015. Deskripsi sikap sosial pada siswa kelas IV penarukan kecamatan buleleng kab buleleng. e-Journal PGSD Universitas Pendidikan Ganesha Jurusan PGSD, 4(1)

Bowyer, J.L., R. Shmulsky., and J.G. Haygreen. 2007. Forest Products and Wood Science: an introduction. Lowa: Blackwell Publishing.

Bachri, Bachtiar S. 2010. Implementasi Pengembangan Content Curriculum dalam Proses Perencanaan Pembelajaran. Jurnal Teknologi Pendidikan, (Online). 10(2), Jurnal-teknologi- pendidikan. tp. ac.id, Diakses 9 April 2018).

Chamin, Asykuri Ibn. Dkk. 2002. Pendidikan Kewarganegaraan. Yogyakarta: Majelis Pendidikan Tinggi, Penelitian dan Pengembangan (Diktilitbang) Pimpinan Pusat Muhammadiyah.

Lickona, Thomas. 2013. Mendidik Untuk Membentuk Karakter Bagaimana Sekolah Dapat Memberikan Pendidikan Tentang Sikap Hormat Dan Bertanggung Jawab. Jakarta: Bumi Aksara

Miles, Matthew B \& Huberman, A Michael, 1992. Analisis Data Kualitatif: Buku Sumber Tentang Metode-metode Baru. Terjemahan Oleh Tjetjep Rohendi Rohidi, 2009. Jakarta: Universitas Indonesia

Nurkaya. 2018. Mengembangkan Aspek Sosial/Kerjasama Siswa Melalui Metode Wisata TK Tirodeceng Pотрапиа Kabupaten Bone. JIKAP PGSD: Jurnal Ilmiah Ilmu Kependidikan, 3(2): 101-107

Rahman, Agus Abdul, 2013. Psikologi Sosial: Integrasi Pengetahuan Wahyu dan Pengetahuan Empirik, Jakarta: Rajawali Pers. 
JIKAP PGSD: Jurnal Ilmiah Ilmu Kependidikan

Ratnasari, Dewi \& Arsana, I Made. 2013. Penanaman Sikap Sopan Santun sebagai Pendidikan Moral kepada Siswa melalui Tata Tertib Sekolah Di SMK PGRI 2 Kertosono. Jurnal Kajian Moral dan Kewarganegaraan (online), 2(1) http://ejournal.unesa.ac.id, Diakses 9 Aprl 2018).

Tim Pusat Pengembangan Profesi Pendidik. 2012. Materi, Struktur, Konsep, dan Keilmuwan Pendidikan Kewarganegaraan: Bahan Belajar Pendidik dan Pelatihan Pasca-Uji Kompetensi Awal Bagi Guru Kelas, Jakarta: Kementerian Pendidikan Dan Kebudayaan.

Utami. 2011. Penanaman Sikap Sosial dalam Pembelajaran IPS di kelas IV SDN Telaga Asih 04 Cikarang barat. Jurnal Pendidikan Ke-SD-an, 5(1).

Ubaedillah, A. Dkk. 2008. Pendidikan Kewarganegaraan (civic Education) Demokrasi, Hak Asasi Manusia, dan Masyarakat Madani. Jakarta: Prenada Media Group.

Wartini, Ida Ayu Km Mira, dkk. 2015. Pengaruh Impelementasi Pendekatan Saintifik terhadap Sikap Sosial dan Hasil Belajar Pkn Di Kelas VI SD Jembatan Budaya, Kuta. E-Jurnal Program Pascasarjana Universitas Pendidikan Ganesha Program Studi Pendidikan Dasar, Vol. 4, 